\title{
Conscious Leadership: A Conceptual Framework of Elements for Short-Term and Long-Term Effectiveness
}

\author{
Prof. E.J. van Niekerk \\ Department of Educational Leadership and Management \\ University of South Africa, South Africa \\ vniekej@unisa.ac.za
}

Prof. P.duP. van Niekerk

Department of Agriculture and Game Management Nelson Mandela Metropolitan University, South Africa pieter.vanniekerk@nmmu.ac.za

Doi:10.5901/mjss.2013.v4n13p283

\begin{abstract}
The idea of conscious leadership refers to the deliberate process whereby a leader takes the essential elements of both the short-term and long-term dimensions of leadership into account in the exercise of leadership. The aim of this article is to provide a frame of reference for promoting conscious leadership, therefore a conceptual framework of both the long term and short term dimensions of conscious leadership is provided. A frame of reference for conscious leadership which is derived from a literature study and conceptual analysis of prominent leadership theories and models is provided. The article concludes that both the good leader and the developing leader need a coherent, comprehensive framework that precisely indicates what good leadership entails in practice and that the framework for conscious leadership provided in the article could assist conscious leadership practice.
\end{abstract}

Keywords: Conscious leadership, long term leadership, short term leadership, leadership effectiveness, conceptual framework

\section{Introduction}

Leadership is widely distributed in the community. Usually we think of those in prominent leadership positions in business, politics, the church and other community structures as leaders, but the primary leaders in the world are actually parents and educators (cf. Tannenbaum, Weschler and Massarik, 1961, Lambert, Collay, Dietz, Kent and Richert, 1996), which gives some indication of how widespread the phenomenon is. Most of the leadership in the world is therefore exercised in an intuitive, non-reflective way as most of these individuals have no formal leadership training.

This is problematic within the organisational context if one assumes that leadership can be improved and shaped through relevant training and development (Bass, 2008, Nohria and Khurana, 2010, Day, 2012), an assumption with which the authors agree. The presupposition underlying the research for this article is thus that leadership in organisations should be a conscious process so as to improve the quality of leadership provided (Bell, 2006). According to Bell (2006), a comprehensive framework that precisely indicates what good leadership entails in practice is required in order to improve leadership practice. Bell (2006 p. xvi) summarises the purpose of such a framework as follows:

Its goal is to integrate all the critical components of leadership into a coherent model that is conceptually sound as well as intensely usable, that unifies all the fragmented viewpoints, theories, concepts, and notions about leadership each of which is part of the story - into an easy-to-grasp, consolidated, workable approach.

Although leadership is a well-researched study field within which a lot of publications have seen the light, there still seems to be a need for the type of framework to which Bell refers. The authors of this article are aware of leadership theory being a dynamic, complex and evolving field of research (Coleman, 2003, Bass, 2008, Nohria and Khurana, 2010), and that there is considerable contestation as to the real meaning of the concept leadership. Even this should however not be an excuse for not providing clear-cut direction regarding good leadership practice based on research. The aim of this article is therefore to provide a framework for conscious long-term and short-term (or situational) leadership and to integrate these two dimensions of leadership into an integrated model for conscious, effective 
leadership. In this article, the idea of conscious leadership refers to the deliberate process whereby a leader takes the elements of both long-term and short-term leadership effectiveness into account in the execution of leadership. These elements form a frame of reference within an integrated model of leadership for use by the conscious leader in order to promote leadership effectiveness. Effective leadership will be contextualised next in terms of the long-term and shortterm leadership dimensions, followed by the methodology applied in the research. Thereafter the short-term and longterm dimensions of the framework are presented consecutively, followed by a discussion presenting the model of leadership integrating these two dimensions.

\section{Leadership Effectiveness}

There are numerous definitions of leadership, but most have in common that leadership is about influencing people to reach goals (Van Niekerk, 1995). This accords with the definitions by Kleon and Rinehart (1998) and Harris and Muijs (2005) of leadership as a role that leads towards goal achievement, involves interaction of influence and usually results in some form of changed structure of behaviour of groups, organisations or communities.

The above definition of leadership implies that leadership should be seen as a process of influencing people to reach organisational goals. From the definition, it is implied that the process of effective leadership will have as its result the achievement of the desired goals. The leader thus has to identify with organisational goals.

Having said this, one should however keep in mind that the distinction that is made in this article between shortterm and long-term leadership has implications for the way effectiveness is conceptualised. The short-term view of leadership implies that leadership takes place in a particular situation. It is important for the organisation that the leader understands the situation correctly in order to provide relevant leadership in the given situation. This will ensure that the best results are achieved under the specific circumstances (Van Deventer and Kruger, 2003, Ayman and Adams, 2012, Van Niekerk, 2012). It is, however, also the case that the conditions and criteria for effective leadership will change when the situations, under which leadership is provided, change. Leaders may, for instance, find it difficult to adopt an appropriate leadership style for every change in the environment. There are thus shortcomings with regard to effectiveness in this short-term or situational view of leadership (Van Niekerk, 1995, Van Niekerk, 2012).

The answer to leadership effectiveness should thus be sought in the view of leadership as a long-term process. The authors of this article accept that no leader has the ability to handle every situation effectively, and leaders will thus possibly provide ineffective or less successful leadership under some conditions. The effectiveness of leadership should therefore not be measured only against the short-term dimension, but against the measure by which the leader influences the progress towards the goals of the organisation as a whole in the long run. The function of the leader should therefore not only be seen in terms of the handling of specific situations, but also in terms of the effective guidance provided to the organisation as a whole in the long term (Ciula, 2012).

This does not mean that the short-term dimension is not important in leadership effectiveness. It is precisely important because both the task and the human side of short-term situations should be handled in such a way that progress is made towards organisational goals and the vision of the organisation.

Having clarified the concept effectiveness in terms of the long-term and short-term dimensions of the model to be presented, the focus next will be on how the research was done to construct the frameworks of long-term and short-term leadership.

\section{Methodology}

Bass (2008) is of the opinion that leadership research will expand and that new models of leadership are built on the foundations of the older models and theories. The question confronting researchers is how this building-up process could be done, integrating essential elements of both the long-term and short-term dimensions of leadership into a coherent model for conscious leadership, which is the stated aim of this article. The method used to fulfil this purpose is a reflective and analytical study of selected well-known leadership theories and models to identify the elements of shortterm leadership effectiveness and to conceptually integrate these elements into a framework for short-term leadership effectiveness. The long-term framework was established through a conceptual integration of accepted ideas on leadership, which the authors found in general leadership literature. The theories studied for conceptualising the shortterm dimension are the trait theory; the behavioural theories of McGregor, Lickert, Blake and Mouton and the Ohio State model; the situational theories of Tannenbaum and Schmidt, Fiedler, the path-goal model of House, the Vroom-Yetton model and Hersey and Blanchard's model. The presupposition underlying this conceptual analysis to build a framework 
for conscious leadership is that other researchers have already incorporated into their research on leadership, their models and theories those elements that need to be identified, but that few models or theories have incorporated sufficient elements into a coherent model for conscious leadership, neither have they made the important distinction between the short-term and long-term dimensions of leadership and integrated them into a model for conscious leadership. The elements identified in this research might not represent all elements that can be identified, but in the view of the authors provide a sufficient basis for promoting conscious leadership on the basis of what prominent leadership theories have revealed in the case of the short-term dimension, and in the case of the long-term dimension on the basis of what is promoted in general research literature on leadership.

\section{Conscious Leadership: The Short-Term and Long-Term Dimensions}

In the identification of the elements of leadership effectiveness attention will first be given to the short-term dimension.

\subsection{Short-term dimension}

Knowledge of the leadership theories and models referred to in the exposition of the short-term dimension is presupposed (only prominent theories and models of the past were selected), as the purpose of this article is not to discuss these theories or models or to argue the case for the inclusion of a specific element, but merely to refer to the identified elements contributed by various prominent theories and models to the presented leadership model. Reference to the theories and models researched will thus only be cursory, as the focus will be on the identification of the elements and building up a framework of reference and a coherent model, rather than the discussion of past known theories and models. The origination of the various elements of the framework for short-term leadership is thus acknowledged in the following exposition.

Three aspects, each with various factors under each aspect (See Table 1), were identified from the theories and models as essential to short-term leadership effectiveness, namely the characteristics of the leader, the characteristics of the followers and the characteristics of the situation. The contributions of the various theories and models to these are identified below.

Trait theory. Trait theory research was based on the presupposition that there are certain characteristics inherent to leaders. Although it seems to be true that there are certain characteristics that manifest more clearly with leaders than with followers (such as intelligence, dependability to fulfil responsibilities, knowledge, social involvement and socioeconomic status (Adair, 1973, Bass, 2008), this theory's only contribution was to highlight that the characteristics of the leader are important in leadership theory. No contribution towards the current research was made to the factors under the characteristics of the leader as an important aspect of the short-term dimension.

Behaviour theory. McGregor's (1960 and 1966) well-known Theory X and Y indicates that a leader's view of followers is one of the elements that will influence leadership style. Leaders with a Theory $X$ view of followers will view them as lazy, passive and ambitionless and will therefore be prone to a more autocratic leadership style, while those with a Theory Y view will see followers as motivated, creative and self-controlled and will tend towards using a democratic leadership style. So under the characteristics of the leader, McGregor's theory contributes the factor view of followers that should be taken into account in identifying the most important elements.

Lickert (1961a, 1961b and 1967) contributed to knowledge on leadership through his identification of three variables that will influence leadership, namely trust in subordinates, measure of freedom experienced by followers, and the measure of involvement with followers sought by the leader. So under the characteristics of the leader, Lickert's theory is translated into and contributes to the factors trust in subordinates and freedom allowed to followers that should be taken into account in identifying the most important elements.

The two independent leadership dimensions identified in the Ohio State Model (Szilagyi and Wallace, 1990) with an influence on leadership effectiveness are initiating structure (which refers to the measure that the leader defines and assigns tasks, and courtesy towards followers) and empathy (which refers to the measure to which the leader takes the needs and feelings of followers into account). Under the characteristics of followers, the Ohio State Model is translated into and contributes the factor personal needs and aims, and under the characteristics of the situation it contributes to structuring of the task that should be taken into account in identifying the most important elements.

Blake and Mouton (1964 and 1965) stressed the people and the task dimension of leadership behaviour as important in their research, while they also indicated that a hierarchy of authority is present in all organisations. Not only did they contribute to highlighting the characteristics of the leader, but within that they also contributed the task and 
people orientation factor to this aspect in identifying the most important elements of successful leadership.

Behavioural theories made an important contribution towards expanding knowledge on leadership. According to Bass (2008), behavioural theories increasingly indicate that leadership is an interaction between leader, followers and the situation.

Situational theories. These theories have as their point of departure the presupposition that various variables in the environment (or situation) have an influence on effectiveness of leadership (Van Niekerk, 1995).

Tannenbaum and Schmidt's (1958) leadership continuum made a significant contribution towards identifying important factors that influence short-term leadership effectiveness. They developed their well-known continuum extending from the very autocratic leadership style on the one side to the very participative style on the other extreme to indicate possible leadership styles that may be applied in various situations. They indicate that three interdependent aspects have an important influence on the effectiveness of a particular leadership style, namely the characteristics of the leader, the characteristics of the followers and the characteristics of the situation, thus making provision for all three critical aspects of short-term leadership effectiveness. Factors identified with a bearing on the leader are his or her value system, personality and experience, which are taken up as noteworthy factors under the characteristics of the leader. Readiness to take responsibility, the need to take part in the decision-making process and the identification with organisational goals are also taken up as important elements under characteristics of the followers. Influences within the situation include time pressure, organisational culture and effectiveness of working groups, which are taken up under characteristics of the situation. The researchers acknowledge that Tannenbaum and Schmidt contributed strongly to our understanding of the factors that should be taken into account when researching leadership effectiveness, and to highlight this, their names are indicated first in all instances in the exposition in Table 1.

Fiedler (1967) identified the following three situational variables which influence the effectiveness of a specific leadership style: the leader-subordinate relationship (which refers to the measure by which subordinates trust and respect the leader and obey orders of the leader), the structuring of the task (which refers to the measure by which a task is described and clearly defined) and the position of power of the leader (which refers to the measure by which the position of the leader in the organisation enables the leader to exercise influence on subordinates). The leadersubordinate relationship, the structuring of the task and the position of power of the leader impact on the effectiveness of the leadership style and were taken up with the most important factors under characteristics of the situation.

According to the Path-goal model of House (1971), effective leadership entails selecting a leadership style that is suitable to the specific situation and the needs of followers. He thus highlights the characteristics of the followers and the characteristics of the situation. Employees will accept a specific style in so far as it contributes towards satisfying their immediate and future needs, which translates into the factor personal needs and goals under characteristics of the followers. Under characteristics of the situation, the model contributes the factors structuring of the task and effectiveness of working groups, as these factors were highlighted as situational factors in the model.

The Vroom-Yetton model (1974) indicates that the measure by which subordinates should be involved in decisionmaking will be determined by the situation under which leadership is provided. The leadership style of the leader will also be determined by the measure by which followers are involved in decision-making. The need to take part in the decisionmaking process is therefore contributed as an element by this model under characteristics of the followers.

Hersey and Blanchard's (1969a, 1969b, 1972a and 1972b) model implies that the leader has to take the level of maturity of followers (which is determined by factors such as their willingness to take responsibility, their motivation to excel, their knowledge and experience) into account in determining a suitable leadership style for effectiveness. These factors are included as important elements under characteristics of the followers.

Summarised under the three relevant headings characteristics of the leader, characteristics of the followers and characteristics of the situation, a concise overview of the above exposition is provided in Table 1, indicating also which contribution was made by which model or theory.

Table 1: Aspects and factors with an impact on short-term effective leadership

\begin{tabular}{|l|l|}
\hline Characteristics of the leader (Tannenbaum and Schmidt; Blake and Mouton) \\
\hline Factor contributed & Contributing theory/model \\
\hline View of followers & McGregor \\
\hline Task and people orientation & Blake and Mouton \\
\hline Value system & Tannenbaum and Schmidt \\
\hline Personality & Tannenbaum and Schmidt \\
\hline Experience & Tannenbaum and Schmidt \\
\hline & 0 \\
\hline
\end{tabular}




\begin{tabular}{|l|l|}
\hline Trust in subordinates & Tannenbaum and Schmidt; Lickert; House \\
\hline Freedom allowed to followers & Tannenbaum and Schmidt; Lickert \\
\hline Characteristics of the followers (Tannenbaum and Schmidt; Hersey and Blanchard; House) \\
\hline Readiness to take responsibility & Tannenbaum and Schmidt; Hersey and Blanchardt \\
\hline Need to take part in the decision-making process & Tannenbaum and Schmidt; Vroom and Yetton \\
\hline Identification with organisational goals & Tannenbaum and Schmidt \\
\hline Personal needs and goals & Ohio State Model; House \\
\hline Motivation to excel & Hersey and Blanchard \\
\hline Knowledge & Tannenbaum and Schmidt; Hersey and Blanchard \\
\hline Experience & Tannenbaum and Schmidt; Hersey and Blanchard \\
\hline Characteristics of the situation (Tannenbaum and Schmidt; House) \\
\hline Organisational culture & Tannenbaum and Schmidt \\
\hline Effectiveness of working groups & Tannenbaum and Schmidt; House \\
\hline Time pressure & Tannenbaum and Schmidt \\
\hline Leader-subordinate relationship & Fiedler \\
\hline Structuring of the task & Fiedler; House; Ohio State Model \\
\hline Position of power of the leader & Fiedler \\
\hline Features of the problem that needs to be addressed & Tannenbaum and Schmidt \\
\hline
\end{tabular}

The factors listed in Table 1 are not provided with content substance in this article. They are only listed to aid with the construction of the framework for short-term leadership, but they are thereby also made available for the conscious leader who can provide them with substance through own research on each of these factors, especially by reading the seminal works on leadership by the researchers listed in Table 1.

The above identified aspects and the factors under each can be used as building blocks for the construction of a general conceptual framework of short-term leadership effectiveness.

\subsubsection{A conceptual framework of short-term leadership effectiveness}

An attempt was made (see Figure 1) to align the factors identified above in such a way that they form a general conceptual framework of short-term leadership that can be used by conscious leaders to promote leadership effectiveness. The impact of the aspects (characteristics of the leader, characteristics of the followers and characteristics of the situation) and their factors on the manifestation of leadership style together with an explanation of this framework will be indicated in the following paragraphs. The essence of the framework (which can also be viewed as a model by those who agree to its composition) is captured in Figure 1, which should be interpreted with the ensuing explanation.
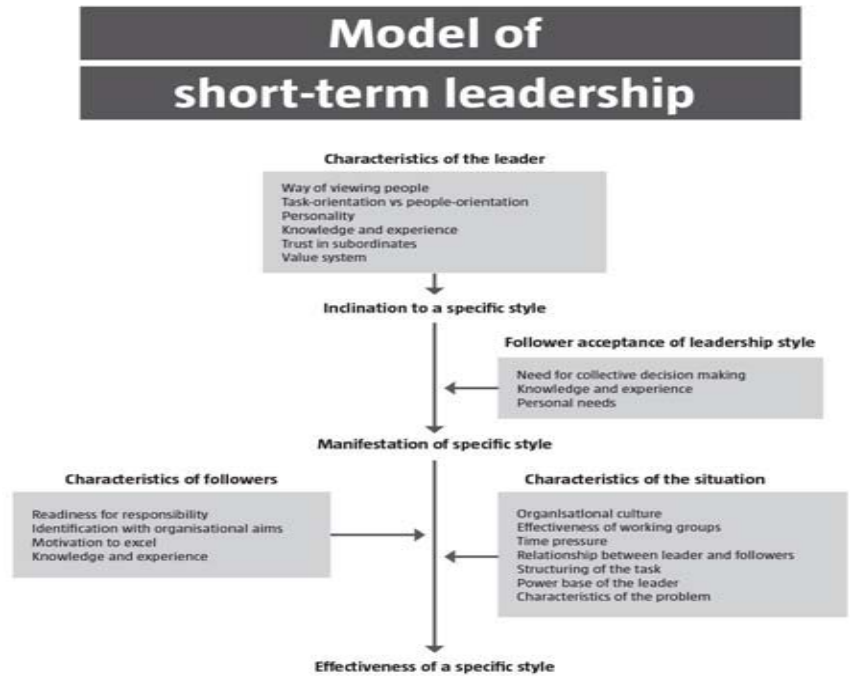

Figure 1: A framework for short-term effective leadership (Van Niekerk, 1995 p. 45, Van Niekerk and Van Niekerk, 2006 and 2009 ) 
The characteristics of the leader will predispose the leader to a specific leadership style. The leader will thus be predisposed to a more democratic or a more autocratic leadership style. This inclination towards a specific leadership style can be moulded to become more flexible through leadership training and experience in the art of leadership. The leader can learn to evaluate the circumstances and to select the appropriate style to suit the situation. Conscious leaders who become aware of the challenges associated with their characteristics as leaders will be better equipped to develop and improve those characteristics that need improvement than those who have no framework to guide them. Likewise, awareness about their own characteristics from a leadership perspective will place them in a better position to capitalise on the strengths associated with their leadership characteristics than those leaders without this awareness (Van Niekerk, 2012).

Although leaders may have a natural tendency towards a specific leadership style they must learn to adapt their leadership style to meet the challenges inherent in a specific situation. Leaders have to try in a conscious way to improve themselves to become better leaders who work towards a more effective leadership style which is in line with changing situations as their organisations move towards their goals in the long run. Leaders also need to be trained to improve their own characteristics as leaders in order to be better leaders (Bell, 2006, Bass, 2008, Masuku, 2012).

The measure by which the leader's leadership style is accepted will depend on the characteristics of the followers. It will also depend on the degree to which the leadership style takes into account the followers' personal needs, knowledge and experience.

The characteristics of the followers as listed in Figure 1 will have an impact on the leadership style adopted by the leader (Van Niekerk, 2012). The characteristics of the followers that exert an influence on the effectiveness of a specific leadership style are related to the ability of the followers to take part in the management of the organisation. A democratic leadership style will, for instance, be ineffective if followers do not have the ability to take part in the decisionmaking process. They will also require motivation, a sense of responsibility, knowledge and experience to make a democratic leadership style work.

An effective leader will strive towards building a successful team of followers with the necessary skills, knowledge and maturity to contribute towards achieving the vision and goals of the organisation.

The situation within which leadership is exercised exerts an influence on the effectiveness of the leadership style, and therefore the characteristics of the situation as listed in Figure 1 will have an impact on the leadership style adopted by the leader (Van Niekerk, 2012). In some instances, an autocratic leadership style might even work better than a democratic style, such as when crucial decisions need to be taken under extreme time constraints. An autocratic leadership style will, however, be ineffective in a situation where highly capable and responsible personnel work in an integrated way, that is, where collective decision-making and teamwork are of the essence. The characteristics of each situation are unique and will affect how effective a particular leadership style is.

The framework tries to capture in Figure 1 that the interaction between the characteristics of the leader and followers leads to a manifestation of a specific leadership style. The effectiveness of the leadership style revealed under specific conditions will depend on the characteristics of the followers and the characteristics of the situation.

On the basis of the explanation in this paragraph, the elements are aligned into what can be considered to be a general conceptual framework of short-term leadership effectiveness to assist the conscious leader.

The short-term dimension of leadership does not stand apart from the long-term dimension, as short-term leadership success is essential in providing the building blocks for long-term success. The way in which a leader engages in the situational dimension on a daily basis will influence the outcomes reached by the leader in the longer term, but there are also deliberate long-term functions to be performed by leaders without which an organisation will not be able to progress towards its intended future.

\subsection{Long-term dimension}

From his literature study of leadership, Van Niekerk (1995) and Van Niekerk and Van Niekerk (2006 and 2009) identified some significant functions that leaders need to execute in order to be effective long-term leaders. In Van Niekerk's (1995) conceptual framework, the first dimension of long-term leadership deals with creating the circumstances and environment within which followers can perform well through executing the functions of envisioning, vision communication and values management in organisations. The second deals with the actions that leaders take to assist followers to perform, namely training and development, and empowerment (Figure 2). The essence of the framework of long-term leadership (which can also be viewed as a model by those who agree to its composition) is captured in Figure 2, which should be interpreted with the ensuing explanation. 


\section{A MODEL FOR LONG-TERM}

\section{EFFECTIVE LEADERSHIP}

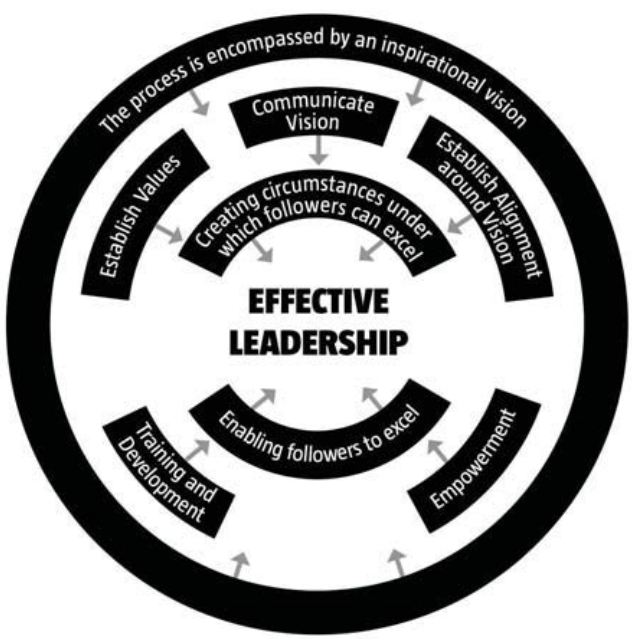

Figure 2: A framework for long-term effective leadership (Van Niekerk, 1995 p. 148)

The above functions are discussed extensively in literature on leadership (Bass, 2008), albeit not within the context that Van Niekerk provides - see Figure 2. Therefore it is not necessary to discuss the leadership functions of envisioning, communication of the vision, values management (the creation of organisational culture), training and development, and empowerment extensively. These are well-known concepts to scholars working in the field of leadership and management. The discussion of these concepts will thus only briefly indicate how they relate to the idea of conscious leadership and relate them to the relevant dimension of long-term leadership where they belong in the framework for long-term leadership.

The vision focuses all the activities in an organisation on the realisation of a common future; therefore, it fulfils an important function in the creation of desirable conditions under which followers can excel. As the vision impacts hugely on the leader's task of influencing the organisation, the development, communication and accomplishment of an organisation's vision is the conscious leader's most important task (Love, 1994, Crainer and Dearlove, 2003). The inspiring communication of the vision to followers provides forward impetus to the organisation; therefore the conscious leader will deliberately focus on communicating the vision in a planned and coordinated way in order to achieve this effect (Neumann and Neumann, 1999, Lewis, 2003). As can be derived from Figure 2, the process of providing effective long-term leadership is encompassed by an inspirational vision. This is inter alia the case because the vision also encompasses all activities of an organisation.

Through values management as a part of the task of the conscious leader taking a long-term perspective, a healthy organisational culture can be built up within which followers can excel. The conscious leader will therefore facilitate in identifying, establishing, nurturing and modelling those values and priorities in an organisation that will create the circumstances within which followers can excel. Long-term leaders therefore need to buy into the idea that values management is a conscious process to which the conscious leader should commit.

As can be derived from Figure 2, the second dimension of long-term leadership relates to the development and empowerment actions that conscious leaders need to take in order to enable followers to achieve organisational aims derived from the vision. Followers need to be trained and developed to acquire the competence, knowledge, values and skills enabling them to contribute towards the achievement of organisational aims. A competent long-term leader will thus emphasise the continual development and training of followers that will enable them to assist the organisation to survive and even thrive in a turbulent environment of constant change (Cronje and Neuland, 2003).

Empowerment as a function of conscious long-term leadership entails that leaders enable followers to make their 
contribution by endowing them with the authority and responsibility to apply what they have been trained and developed to do. Leaders need to provide a secure environment in which followers feel they have the freedom to use their talents and training in service of their organisation, otherwise their potential might be unnecessarily stunted in spite of the training and development opportunities that they have been given.

In this paragraph, the identified important elements of long-term leadership have been aligned into what can be considered to be a general conceptual framework of long-term leadership effectiveness (Figure 2) to assist the conscious leader in the provision of effective leadership. What now remains to be done in order to reach the aim of the article introduced in the introduction, is to integrate the frameworks of long-term and short-term leadership into a model for conscious leadership.

\section{Discussion: Towards an Integrated Model for Conscious Leadership Effectiveness}

It has already been pointed out that the long-term and short-term dimensions of leadership cannot be separated. They are intricately interwoven when applied in leadership practice, and they both contribute towards leadership effectiveness. Although the frameworks have been developed as separate frameworks, their intricate connectedness needs to be acknowledged through combining them into an integrated model for conscious leadership effectiveness. This is attempted in Figure 3 (Van Niekerk, 2012 p. 292), which is self-explanatory in the light of what has already been presented in the other two frameworks, but it will be discussed briefly for clarity and in order to provide the correct perspective.

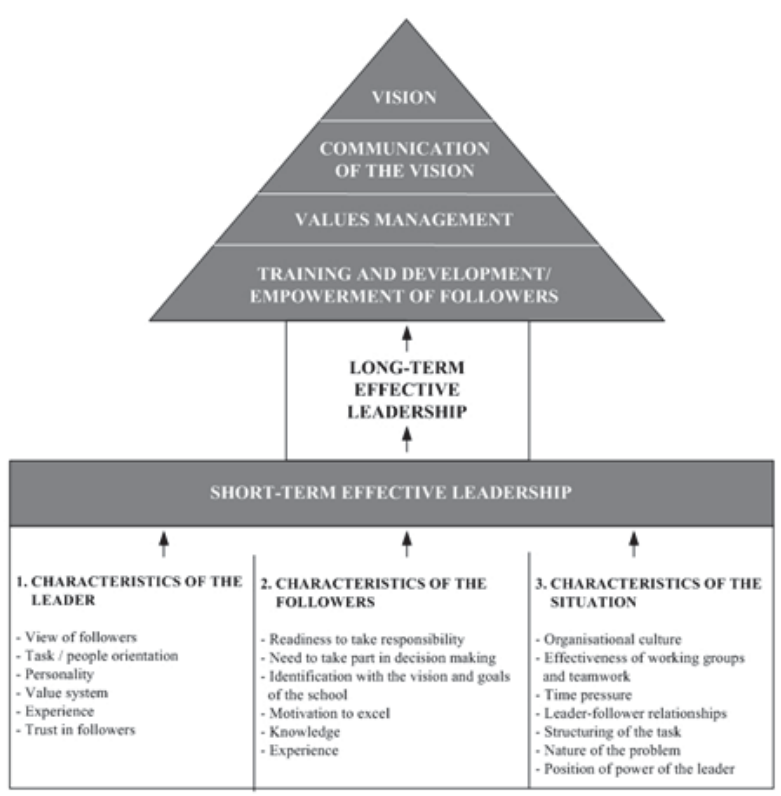

Figure 3: A model for conscious leadership effectiveness (Van Niekerk, 2012 p. 292)

Short-term leadership forms the base of the model in which the characteristics of the leader (determined by various factors), the characteristics of the followers (determined by various factors) and the characteristics of the situation (determined by various factors) are taken into account by the conscious leader in order to provide good leadership, and to follow a relevant leadership style in the day-to-day operation of the organisation and in the many situations confronting the leader on a daily basis. This dimension concerns everyday leadership. If this is performed well it will feed positively into the long-term dimension of leadership in which the conscious leader performs the functions of envisioning, vision communication, values management, and the development and empowerment of followers steering the organisation towards its long-term destination. This features at the top of the model, indicating the upward direction to be taken by the organisation if these long-term functions are performed well.

If leadership can be taught and learnt, as is attempted at the level of higher education and in many in-service 
training courses, workshops and programmes, the implication is also that the most important elements of effective leadership should be consciously reflected on by the conscious leader in his or her leadership practice. The assumption underlying this line of reasoning is that those who are effective leaders will be those who have mastered most of the essential elements of effective leadership. They will be leaders who are able to make a meaningful contribution towards the future of their organisations because they take deliberate ownership of their leadership practice and leadership development through conscious leadership.

\section{Conclusion}

The purpose of this article as stated in the introduction is to provide frameworks for short-term and long-term conscious leadership and to integrate these frameworks into a model for conscious leadership. This was done through a reflective analysis of leadership theories and models of selected prominent leadership researchers and generally accepted ideas featuring in scholarly leadership publications. By identifying and presenting the essential elements of long-term and short-term leadership effectiveness and integrating them into a model for conscious leadership to be able to focus on these elements in the conscious exercise of leadership in organisations, the purpose of the article has been fulfilled.

The authors have no intention of presenting this model as a closed model, as the research was based on a limited number of selected theories, models and literature consulted. Although this model has been used in empirical research (Van Niekerk, 1995, Moosa, 2010, Masuku, 2012, Van Niekerk, 2012), and has been used extensively by the authors in leadership training, further research of both a theoretical and empirical nature is recommended to determine the usefulness of the model in various fields. Precisely because it is presented as an open model that can be extended and adapted, further research is appropriate. The authors feel strongly that the idea of conscious leadership is an important notion that needs to be promoted in order to enrich leadership practice. They therefore recommend that the frameworks/models of short-term and long-term leadership and the model of leadership, or adapted versions thereof, could be integrated into various - if not all - types of leadership training.

\section{References}

Adair, J.E. (1973). Action-centred leadership. London: McGraw-Hill.

Ayman, R., \& Adams, S. (2012). Contingencies, context, situation, and leadership. In D.V. Day, \& J. Antonakis (Eds.), The nature of leadership. (2nd ed.). (pp. 218-255). Los Angeles: Sage.

Bass, B.M. (2008). The Bass handbook of leadership. Theory, research, and managerial applications. (4th ed.). New York: Free Press.

Bell, A. (2006). Great leadership: What it is and what it takes in a complex world. Mountain View, CA: Davies-Black.

Blake, R.R., \& Mouton, J.S. (1964). The managerial grid. Houston, TX: Gulf.

Blake, R.R., \& Mouton, J.S. (1965). A 9,9 approach for increasing organizational productivity. In E.H. Schein, \& W.C. Bennis (Eds.), Personal and organizational change through group methods. New York: Wiley.

Ciula, J.B. (2012). Ethics and effectiveness: The nature of good leadership. In D.V. Day, \& J. Antonakis (Eds.), The nature of leadership. $\left(2^{\text {nd }}\right.$ ed.). (pp. 508-540). Los Angeles: Sage.

Coleman, M., (2003). Theories of leadership. In M. Coleman, (Ed.), Leadership and strategic management in South African schools. (pp. 155-172). London: The Commonwealth Secretariat.

Crainer, S., \& Dearlove, D. (2003). Business: The universe and everything. Chichester: Capstone.

Cronje, S., \& Neuland, E. (2003). Strategy implementation: new realities. Management Today, 18 (10), 22-26.

Day, D.V. (2012). The nature of leadership development. In D.V. Day, \& J. Antonakis (Eds.), The nature of leadership. (2nd ed.). (pp. 108140). Los Angeles: Sage.

Day, D.V., \& Antonakis, J. (2012). Leadership: Past, present, and future. In D.V. Day, \& J. Antonakis (Eds.), The nature of leadership. (2nd ed.). (pp. 3-25). Los Angeles: Sage.

Fiedler, F.E. (1967). A theory of leadership effectiveness. New York: McGraw-Hill.

Harris, A., \& Muijs, D. (2005). Improving schools through teacher leadership. Berkshire: Open University Press.

Hersey, P., \& Blanchard, K.H. (1969a). Life cycle theory of leadership. Training and Development Journal, 23, 26-34.

Hersey, P., \& Blanchard, K.H. (1969b). Management of organizational behaviour. Englewood Cliffs, NJ: Prentice-Hall.

Hersey, P, \& Blanchard, K.H. (1972a). The management of change: Change and the use of power. Training and Development Journal, $26(1), 6-10$.

Hersey, P, \& Blanchard, K.H. (1972b). The management of change: Change and the use of power. Training and Development Journal, 26(2), 20-24

House, R.J. (1971). A path goal theory of leader effectiveness. Administrative Science Quarterly, 16, 321-338.

Kleon S., \& Rinehart, S. (1998). Leadership skill development of teen leaders. Journal of Extension, 36(3), 1-5.

Lambert, L., Collay, M., Dietz, M.E., Kent, K. \& Richert, A.E. (1996). Who will save our schools? Teachers as constructivist leaders. Thousand Oaks, CA: Corwin. 
Lewis, L. (2003). The reinvention of leadership for the new millennium. Management Today, 18 (10), 8-10.

Lickert, R. (1961a). New patterns of management. New York: McGraw-Hill.

Lickert, R. (1961b). An emerging theory of organizations, leadership and management. In L. Petrullo, \& B.M. Bass (Eds.), Leadership and interpersonal behaviour. New York: Holt, Rinehart \& Winston.

Lickert, R., (1967). The human organization. New York: McGraw-Hill.

Love, J.R. (1994). Liberating leaders from the superman syndrome. Lanham: University Press of America.

Masuku, S. (2012). The instructional leadership role of the high school head in creating a culture of teaching and learning in Zimbabwe. Unpublished Doctoral Thesis. Pretoria: University of South Africa.

Moosa, S.O. (2010). A school leadership perspective on the role of emotional intelligence in the development of secondary school student leaders. Unpublished Master's Dissertation. Pretoria: University of South Africa.

McGregor, D. (1960). The human side of enterprise. New York: McGraw-Hill.

McGregor, D. (1966). Leadership and motivation. Cambridge, MA: M.I.T. Press.

Neumann, Y., \& Neumann, E.F. (1999). The president and the college bottom line: the role of strategic leadership styles. The International Journal of Educational Management, 13 (2), 73-79.

Nohria, M., \& Khurana, R. (2010). Handbook of leadership theory and practice. Boston, Mass.: Harvard Business Press.

Szilagyi, A.D., \& Wallace, M.J. (1990). Organisational behaviour and performance. (5 $5^{\text {th }}$ ed.). New York: Harper-Collins.

Tannenbaum, R., \& Schmidt, W.H. (1958). How to choose a leadership pattern. Harvard Business Review, 36(2), 95-101.

Tannenbaum, R., Weschler, I.R., \& Massarik, F. (1961). Leadership and organisation. New York: McGraw-Hill.

Van Deventer, I., \& Kruger, A.G. (Eds.). (2003). An educator's guide to school management skills. Van Schaik: Pretoria.

Van Niekerk, E.J. (2012). Education leadership. In G.M. Steyn, \& E.J. van Niekerk. Human resource management in education. (3rd ed.). (pp. 292-324). Pretoria: Unisa Press.

Van Niekerk, E.J., \& Van Niekerk, P.duP. (2006). Strategic management in South African education: the leadership dimension. Africa Education Review, 3(1), 84-99.

Van Niekerk, E.J., \& Van Niekerk, P.duP. (2009). Managing change in education through a model of long-term leadership and shortterm leadership, Journal of Educational Studies, 8(1), 1-21.

Van Niekerk, P.duP. (1995). 'n Evaluering van die doeltreffendheid van leierskap van boere in die Gamtoosvallei. Unpublished Master's Dissertation. Port Elizabeth: Port Elizabeth Technicon, Port Elizabeth.

Vroom, V.H., \& Yetton, P.W. (1974). Leadership and decision-making. New York: Wiley. 